\section{Respiratory Syncytial Virus Infections in a Neonatal Intensive Care Unit - Louisiana, December 2017}

Erica J. Washington, $\mathrm{MPH}^{1}$; Erica Billig Rose, $\mathrm{PhD}^{2,3}$; Gayle E. Langley, $\mathrm{MD}^{3}$; Julie P. Hand, $\mathrm{MSPH}^{1}$; Isaac Benowitz, $\mathrm{MD}^{4}$; Susan I. Gerber, $\mathrm{MD}^{3}$; Andrea L. Salinas, MPH ${ }^{1}$; Ashley L. Terry, MPH ${ }^{1}$; Julius L. Tonzel, $\mathrm{MPH}^{1}$; Theresa M. Sokol, MPH${ }^{1}$; Andrew T. Smith, $\mathrm{MPH}^{1}$; Gillian J. Richardson, $\mathrm{MPH}^{1}$

In December 2017, the Louisiana Department of Health was notified of seven cases of respiratory syncytial virus (RSV) infection in a five-unit (units A-E), 84-bed neonatal intensive care unit (NICU) that included 66 individual infant rooms. The first case occurred in an infant who had been discharged postpartum from the NICU 30 days earlier and was readmitted for respiratory distress (day 0), approximately 2 weeks after the peak in reported RSV cases in Louisiana (mid-November) (1). The other six infants had at least one respiratory symptom while in the NICU postpartum. Upon identification of the first case, the facility implemented contact precautions for symptomatic infants, and NICU staff members were asked to report any respiratory symptoms. Nasopharyngeal specimens were obtained from infants who had rhinorrhea, cough, or nasal congestion. Nasopharyngeal swabs were also obtained from asymptomatic infants in two of the three units where the seven identified patients resided. A case was defined as laboratory-confirmed RSV infection in an NICU patient during December 2017. After consultation with CDC, a team of Louisiana Department of Health epidemiologists visited the facility 3 days after notification to review medical charts, observe infection control procedures, interview NICU staff members, and determine measures to prevent further transmission.

All seven patients were born at the facility. The first identified RSV case occurred in the only patient who had been discharged. Symptom onsets occurred over an 11-day period (Figure). Six of the seven patients were born at 25-36 weeks' gestational age. One patient was housed in unit $\mathrm{A}$, one in unit $\mathrm{B}$, and five in unit $\mathrm{C}$. The median age of patients from birth to symptom onset was 15 days (range $=7-147$ days). The most commonly observed signs and symptoms among patients with RSV included cough (four patients), nasal congestion (seven), tachypnea (four), tachycardia (four), and poor feeding (four). One patient required bilevel positive airway pressure, another required continuous positive airway pressure, and a third required endotracheal intubation and mechanical ventilation. Hospital staff members reported that two of the patients
FIGURE. Day of symptom onset among seven patients with respiratory syncytial virus (RSV) infection in a neonatal intensive care unit (NICU) — Louisiana, December 2017*

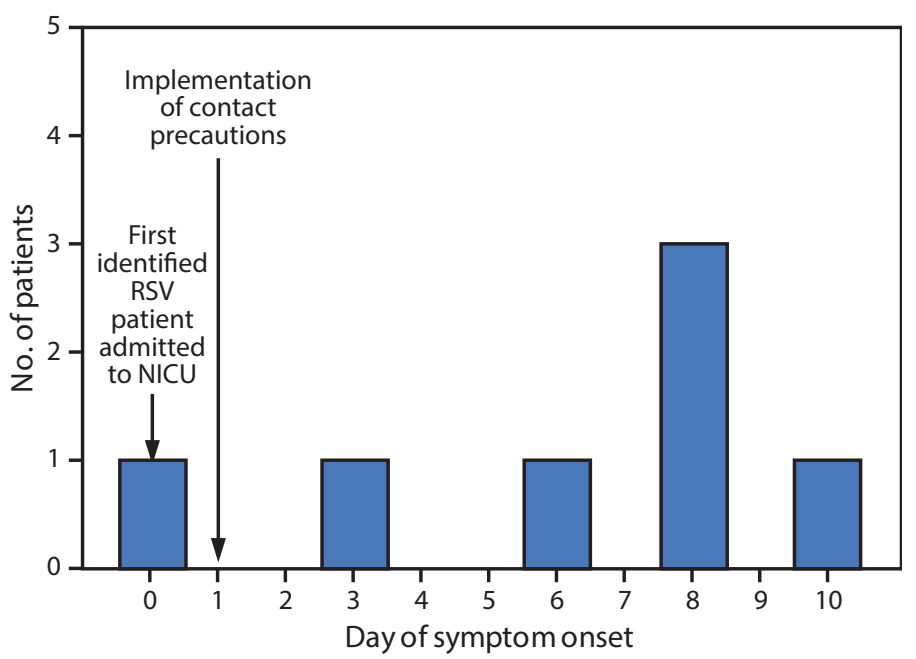

* Infection presentation by location: day 0 (unit A), days 3-8 (unit C), and day 10 (unit B).

were visited by ill family members despite a policy prohibiting ill visitors. No staff members reported symptoms.

Respiratory specimens from the seven patients were tested at the hospital laboratory by real-time reverse transcriptionpolymerase chain reaction; all were positive for RSV and negative for influenza, coronavirus, parainfluenza, and human metapneumovirus. Nasal swabs were sent to CDC for subtypespecific testing by real-time reverse transcription-polymerase chain reaction. All seven specimens were identified as RSV type B. Enterovirus or rhinovirus was also detected in one patient's specimen. No additional patients had RSV detected in any specimens.

During the facility visit, epidemiologists reviewed infection control policies, availability and use of personal protective equipment, infection control signage, visitor education, and environmental cleaning. Louisiana Department of Health recommended that the facility, in addition to the standard and contact precautions already in place, implement droplet precautions; restrict visitation from sick persons and children aged $<12$ years; that visitors, including family members, wear facemasks when entering patient rooms; and that the facility increase hand hygiene stations, enhance environmental cleaning, and designate certain staff members to care for RSV patients. No additional cases were identified during the 14 days following the last observed symptom onset, and all seven patients recovered. 
RSV is a leading cause of lower respiratory tract infections in young children worldwide. In the United States, infants aged $\leq 2$ months have an estimated hospitalization rate of 17.9 per 1,000 each year (2). During the RSV season (typically fall through spring), health care facilities are at increased risk for nosocomial transmission of RSV, although such transmission is rarely identified and reported to public health officials. Transmission within NICUs is of particular concern because of the presence of infants at high risk, including preterm infants and infants with underlying medical conditions (3). To prevent RSV transmission in health care facilities, standard and contact precautions (4), cohorting of symptomatic patients and staff members, excluding symptomatic visitors and young siblings, and emphasizing hand hygiene practices are recommended (3).

\section{Acknowledgments}

Respiratory Virus Diagnostics Program, Division of Viral Respiratory Diseases, CDC; Infectious Disease Epidemiology Section, Louisiana Department of Health; Office of Public Health Laboratory, Louisiana Department of Health; Lindsay Kim, MD, Division of Viral Respiratory Diseases, CDC

Corresponding author: Erica J. Washington, Erica.Washington@LA.gov, 504-568-8319.
${ }^{1}$ Louisiana Department of Health, Office of Public Health, Infectious Disease Epidemiology Section; ${ }^{2}$ Epidemic Intelligence Service, CDC; ${ }^{3}$ Division of Viral Diseases, National Center for Immunization and Respiratory Diseases, CDC; ${ }^{4}$ Division of Healthcare Quality Promotion, National Center for Emerging and Zoonotic Infectious Diseases, CDC.

All authors have completed and submitted the ICMJE form for disclosure of potential conflicts of interest. No potential conflicts of interest were disclosed.

\section{References}

1. CDC. Respiratory syncytial virus trends and surveillance. Atlanta, GA: US Department of Health and Human Services, CDC; 2018. https:// www.cdc.gov/rsv/research/us-surveillance.html

2. Hall CB, Weinberg GA, Blumkin AK, et al. Respiratory syncytial virus-associated hospitalizations among children less than 24 months of age. Pediatrics 2013;132:e341-8. PubMed https://doi.org/10.1542/ peds.2013-0303

3. American Academy of Pediatrics. Respiratory syncytial virus. In: Kimberlin DW, Brady MT, Jackson MA, Long SS, eds. Red book: 2018 report of the Committee on Infectious Diseases. American Academy of Pediatrics; 2018;682-92.

4. Healthcare Infection Control Practices Advisory Committee. Core infection prevention and control practices for safe healthcare delivery in all settings-recommendations of the Healthcare Infection Control Practices Advisory Committee. Atlanta, GA: US Department of Health and Human Services, CDC; 2017. https://www.cdc.gov/hicpac/pdf/ core-practices.pdf 